\title{
Electronic and Electrical Calculations
}




\section{Macmillan Master Series}

Accounting

Advanced English Language

Advanced Pure Mathematics

Arabic

Banking

Basic Management

Biology

British Politics

Business Administration

Business Communication

Business Law

C Programming

Catering Science

Catering Theory

Chemistry

COBOL Programming

Commerce

Computers

Databases

Economic and Social History

Economics

Electrical Engineering

Electronic and Electrical Calculations

Electronics

English as a Foreign Language

English Grammar

English Language

English Literature

English Spelling

French

French 2
German

German 2

Human Biology

Italian

Italian 2

Japanese

Manufacturing

Marketing

Mathematics

Mathematics for Electrical and Electronic Engineering

Modern British History

Modern European History

Modern World History

Pascal Programming

Philosophy

Photography

Physics

Psychology

Restaurant Service

Science

Social Welfare

Sociology

Spanish

Spanish 2

Spreadsheets

Statistics

Study Skills

Word Processing 


\section{Mastering}

\section{Electronic and Electrical Calculations}

Noel M. Morris 


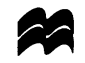

(C) Noel M. Morris 1996

All rights reserved. No reproduction, copy or transmission of this publication may be made without written permission.

No paragraph of this publication may be reproduced, copied or transmitted save with written permission or in accordance with the provisions of the Copyright, Designs and Patents Act 1988, or under the terms of any licence permitting limited copying issued by the Copyright Licensing Agency, 90 Tottenham Court Road, London W1P 9HE.

Any person who does any unauthorised act in relation to this publication may be liable to criminal prosecution and civil claims for damages.

First published 1996 by

MACMILLAN PRESS LTD

Houndmills, Basingstoke, Hampshire RG21 6XS

and London

Companies and representatives

throughout the world

ISBN 978-0-333-63345-8

ISBN 978-1-349-13705-3 (eBook)

DOI 10.1007/978-1-349-13705-3

A catalogue record for this book is available from the British Library.

$\begin{array}{llllllllll}10 & 9 & 8 & 7 & 6 & 5 & 4 & 3 & 2 & 1\end{array}$

$\begin{array}{llllllllll}05 & 04 & 03 & 02 & 01 & 00 & 99 & 98 & 97 & 96\end{array}$

Copy-edited and typeset by Povey-Edmondson

Okehampton and Rochdale, England 
This book is dedicated to Barbara, Helen, Ian, Kathy and Anthony 

1 Introduction to electronic and electrical equations and resistance

1.1 Introduction

1.2 Transposition of equations

1.3 Units in electronics and electrical engineering 5

$\begin{array}{lll}1.4 & \text { Conversion of unit size } & 6\end{array}$

$\begin{array}{lll}1.5 & \text { Ohm's law } & 8\end{array}$

$\begin{array}{llr}1.6 & \text { Resistivity and resistance } & 9\end{array}$

$\begin{array}{lll}1.7 & \text { Temperature coefficient of resistance } & 10\end{array}$

$\begin{array}{lll}1.8 & \text { Resistance colour code } & 14\end{array}$

1.9 Computer listings in the BASIC language 16 $\begin{array}{ll}\text { Exercises } & 18\end{array}$

Summary of important facts 19

2 Resistor circuits $\quad \mathbf{2 1}$

$\begin{array}{lll}2.1 & \text { Introduction } & 21\end{array}$

$\begin{array}{lll}2.2 & \text { Resistors in series } & 21\end{array}$

$\begin{array}{lll}2.3 & \text { Parallel circuits } & 23\end{array}$

2.4 Series-parallel circuits 26

$\begin{array}{lll}2.5 & \text { The Wheatstone bridge } & 31\end{array}$

2.6 Computer listings $\quad 34$

$\begin{array}{ll}\text { Exercises } & 37\end{array}$

Summary of important facts $\quad 40$

3 Power, energy and efficiency $\quad 42$

$\begin{array}{ll}3.1 \text { Introduction } & 42\end{array}$

3.2 Power 42

3.3 Energy consumption 45

$\begin{array}{lll}3.4 & \text { Efficiency } & 48\end{array}$

3.5 Computer listing $\quad 50$

$\begin{array}{ll}\text { Exercises } & 52\end{array}$

Summary of important facts $\quad 53$ 
4 Network theorems $\quad \mathbf{5 5}$

4.1 Introduction $\quad 55$

4.2 Kirchhoff's laws $\quad 55$

4.3 Thévenin's theorem $\quad 64$

$\begin{array}{lll}4.4 & \text { Norton's theorem } & 72\end{array}$

4.5 Conversion between Thévenin and Norton circuits 78

4.6 The maximum power transfer theorem 79

$\begin{array}{ll}4.7 & \text { Computer listings } \\ & 80\end{array}$

\begin{tabular}{lr} 
Exercises & 82 \\
\hline
\end{tabular}

Summary of important facts $\quad 85$

5 Capacitors and capacitor circuits $\quad \mathbf{8 6}$

$\begin{array}{lll}5.1 & \text { Introduction } & 86\end{array}$

5.2 Capacitance of a parallel-plate capacitor 86

5.3 Electric field strength and electric flux density 88

$\begin{array}{lll}5.4 & \text { Charge and energy stored by a capacitor } & 89\end{array}$

$\begin{array}{lll}5.5 & \text { Series-connected capacitors } & 90\end{array}$

5.6 Parallel-connected capacitors 94

$\begin{array}{ll}5.7 & \text { Series-parallel capacitor circuits } \\ 5.8 & 96\end{array}$

5.8 Computer listings 102

$\begin{array}{ll}\text { Exercises } & 104\end{array}$

Summary of important facts 106

6 Inductance and mutual inductance $\quad 108$

$\begin{array}{ll}6.1 & \text { Introduction } \\ 6.2 & 108\end{array}$

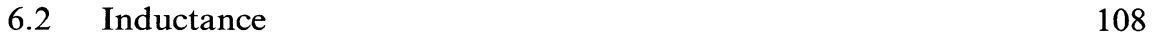

$\begin{array}{lll}6.3 & \text { e.m.f. induced in an inductor } & 111\end{array}$

6.4 Energy stored in the magnetic field of an inductor 113

$\begin{array}{ll}\text { 6.5 Mutual inductance } & 114\end{array}$

$\begin{array}{lll}\text { 6.6 Series-connected inductors } & 117\end{array}$

$\begin{array}{lr}6.7 & \text { Parallel-connected inductors } \\ 6.8 & 118\end{array}$

$\begin{array}{ll}\text { 6.8 Computer listing } & 121\end{array}$

Exercises $\quad 123$

Summary of important facts $\quad 124$

7 Electromagnetism $\quad 127$

$\begin{array}{lll}7.1 & \text { Introduction } & 127\end{array}$

$\begin{array}{lll}7.2 & \text { e.m.f. induced in a conductor } & 127\end{array}$

$\begin{array}{lll}7.3 & \text { Force acting on a current-carrying conductor } & 129\end{array}$

$\begin{array}{lll}7.4 & \text { Flux and flux density } & 130\end{array}$

$\begin{array}{lll}7.5 & \text { Magnetomotive force and magnetising force } & 131\end{array}$

$\begin{array}{llr}7.6 & \text { Permeability } & 132\end{array}$

$\begin{array}{lll}7.7 & \text { Reluctance } & 133\end{array}$

$\begin{array}{lll}7.8 & \text { Series-connected magnetic circuits } & 134\end{array}$

$\begin{array}{ll}7.9 & \text { Parallel magnetic circuits } \\ \end{array}$ 
$\begin{array}{lll}7.10 & \text { Magnetic leakage and fringing } & 140\end{array}$

7.11 Computer listing 141

Exercises 144

Summary of important facts $\quad 147$

8 Alternating current 149

$\begin{array}{lll}8.1 \text { Introduction } & 149\end{array}$

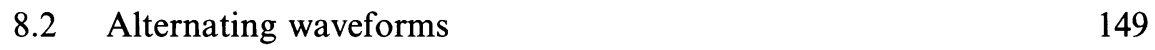

8.3 Frequency, periodic time, angular frequency and wavelength 152

8.4 Average value of a wave 153

8.5 Root-mean-square (r.m.s.) value of a wave 155

8.6 Form factor and peak factor (or crest factor) 156

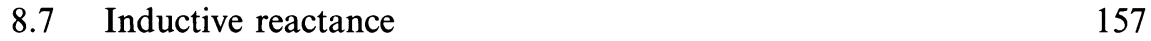

8.8 Alternating current in a pure inductor 158

$\begin{array}{ll}8.9 \text { Capacitive reactance } & 159\end{array}$

$\begin{array}{ll}8.10 & \text { Alternating current in a pure capacitor } \\ 8 & 160\end{array}$

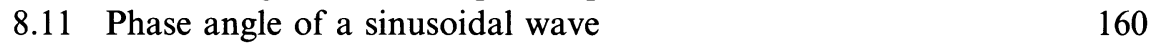

$\begin{array}{ll}8.12 & \text { Introduction to phasors } \\ 863\end{array}$

8.13 Addition of phasors 165

8.14 Conversion between rectangular and polar coordinates 166

$\begin{array}{ll}8.15 & \text { Subtraction of phasors } \\ 8 & 170\end{array}$

8.16 Computer listings $\quad 173$

$\begin{array}{ll}\text { Exercises } & 178\end{array}$

$\begin{array}{ll}\text { Summary of important facts } & 180\end{array}$

9 Alternating current circuits 183

$\begin{array}{lll}9.1 \text { Introduction } & 183\end{array}$

9.2 The $R-L$ series circuit 183

9.3 The $R$ - $C$ series circuit $\quad 187$

9.4 The series $R-L-C$ circuit 190

9.5 The two-branch $R-L$ parallel circuit 194

9.6 The two-branch $R$ - $C$ parallel circuit 196

9.7 A practical parallel circuit $(R-L$ in parallel with $C) \quad 198$

9.8 BASIC language programs for the solution of series and
parallel circuits

Exercises 206

Summary of important facts 209

10 Volt-amperes (VA), power, reactive VA and power factor correction 213

$\begin{array}{lll}10.1 \text { Introduction } & 213\end{array}$

$\begin{array}{lll}10.2 & \text { The power triangle } & 213\end{array}$

$\begin{array}{lll}10.3 & \text { Power factor } & 216\end{array}$

10.4 Power factor of combined loads 218

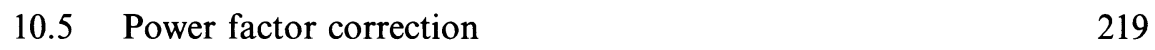

10.6 Computer listings 223

Exercises $\quad 226$

Summary of important facts $\quad 227$ 
$\begin{array}{lll}11.1 & \text { Introduction } & 229\end{array}$

$\begin{array}{ll}11.2 & \text { The series resonant circuit } \\ 113 & 229\end{array}$

11.3 $Q$-factor of a series resonant circuit 231

11.4 Pure $L$ in parallel with pure $C$ at resonance 232

11.5 $L-R$ in parallel with pure $C$ at resonance 234

$11.6 Q$-factor of a parallel circuit at resonance 235

$\begin{array}{ll}11.7 \text { Computer listing } & 237\end{array}$

Exercises $\quad 238$

Summary of important facts 240

12 Transformers $\quad 242$

12.1 Introduction $\quad 242$

12.2 Basic principles $\quad 242$

12.3 e.m.f. equation 243

12.4 Voltage, current and turns ratio 244

12.5 Transformer efficiency 246

12.6 Relationship between the copper loss and the load kVA 248

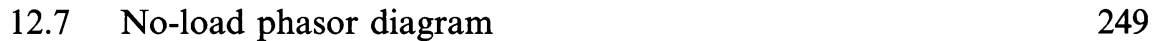

12.8 Phasor diagram for a loaded transformer 252

12.9 Maximum power transfer to a resistive load 254

$\begin{array}{ll}12.10 \text { The auto-transformer } & 255\end{array}$

12.11 Computer listing 257

Exercises $\quad 259$

Summary of important facts $\quad 261$

13 Balanced three-phase systems $\quad 264$

13.1 Introduction 264

13.2 Three-phase waveforms $\quad 264$

13.3 Phase and line voltage 266

13.4 Phase and line voltage of a balanced star-connected system 266

13.5 Phase and line current in a balanced star-connected system 268

13.6 Three-phase, four-wire, star-connected system 268

13.7 Balanced supply and balanced star-connected load 269

13.8 Summary of line and phase values for a balanced star-connected system $\quad 270$

13.9 Balanced supply and unbalanced star-connected load 270

13.10 Delta connection or mesh connection 276

13.11 Summary of line and phase values for a balanced
delta-connected system

13.12 Power, VA and VAr consumed by a balanced three-phase load 278

$\begin{array}{ll}13.13 \text { Computer listing } & 279\end{array}$

Exercises 280

Summary of important facts 283 
$\begin{array}{lll}14.1 & \text { Introduction } & 284\end{array}$

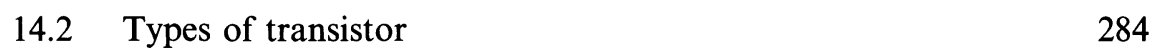

$14.3 \quad p-n-p$ transistor configurations 285

14.4 Common-emitter bias circuits 285

14.5 Common-emitter class A amplifier 291

14.6 The a.c. load line or dynamic load line 295

14.7 The emitter follower circuit 298

$\begin{array}{lll}14.8 & \text { Field-effect transistors } & 300\end{array}$

$\begin{array}{ll}14.9 \text { Computer listing } & 300\end{array}$

Exercises $\quad 302$

Summary of important facts 303

15 Operational amplifier circuits $\quad 305$

15.1 Introduction 305

15.2 Features of an ideal operational amplifier 305

$\begin{array}{ll}\text { 15.3 An inverting amplifier } & 306\end{array}$

15.4 A phase inverting summing amplifier 308

$\begin{array}{ll}15.5 & \text { A non-inverting amplifier } \\ 15.6 & 309\end{array}$

15.6 A differential input (instrumentation) amplifier 310

$\begin{array}{lll}15.7 & \text { An electronic integrator circuit } & 313\end{array}$

$\begin{array}{lll}15.8 & \text { Computer listings } & 314\end{array}$

Exercises $\quad 316$

Summary of important facts $\quad 317$

16 Oscillators $\quad 318$

16.1 Introduction 318

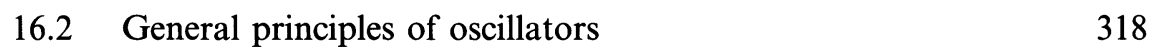

$16.3 R$ - $C$ phase-shift oscillator 318

$\begin{array}{ll}16.4 & \text { The Wein-bridge oscillator } \\ 16.5 & 320\end{array}$

16.5 The twin-T oscillator 321

$\begin{array}{lll}16.6 & \text { The Colpitts oscillator } & 322\end{array}$

16.7 The Hartley oscillator 323

16.8 The tuned collector oscillator 325

$\begin{array}{ll}16.9 & \text { The astable multivibrator } \\ 16.10 & 326\end{array}$

16.10 Computer listing 328

Exercises $\quad 330$

Summary of important facts 331

17 Attenuators and filters 333

17.1 Introduction 333

17.2 The decibel 333

$\begin{array}{lll}17.3 & \text { Using decibel ratios } & 337\end{array}$

17.4 T- and $\pi$-attenuators $\quad 338$

$\begin{array}{lll}17.5 & \text { Symmetrical T-attenuator } & 339\end{array}$

$\begin{array}{lll}17.6 & \text { Symmetrical } \pi \text {-attenuator } & 340\end{array}$

$17.7 \mathrm{~T}-\pi$ and $\pi-\mathrm{T}$ conversion for resistive networks 341

17.8 Filter circuits 343 
17.9 Passive $R$ - $C$ low-pass filter $\quad 344$

$\begin{array}{lll}17.10 & \text { Passive } R-C \text { high-pass filter } & 346\end{array}$

17.11 Active $R$ - $C$ filters $\quad 347$

17.12 Computer listings $\quad 349$

Exercises $\quad 354$

Summary of important facts $\quad 355$

18 Binary systems and computer logic $\quad 357$

$\begin{array}{lll}18.1 & \text { Introduction } & 357\end{array}$

$\begin{array}{lll}\text { 18.2 Basis of numbering systems } & 357\end{array}$

$\begin{array}{lll}18.3 & \text { Representing a number of any base } & 358\end{array}$

$\begin{array}{lll}18.4 & \text { Bits and bytes } & 359\end{array}$

18.5 Converting an integer of any base into decimal 359

$\begin{array}{ll}\text { 18.6 Converting a decimal integer into another radix } & 359\end{array}$

$\begin{array}{ll}\text { 18.7 Numbers having a fractional part } & 360\end{array}$

18.8 Pure binary addition and truth tables 361

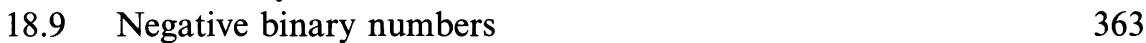

$\begin{array}{lll}18.10 & \text { Binary subtraction } & 364\end{array}$

$\begin{array}{ll}18.11 & \text { Binary multiplication } \\ 18.12 & 366\end{array}$

$\begin{array}{lll}18.12 & \text { Binary division } & 367\end{array}$

$\begin{array}{lll}18.13 & \text { Logic gates } & 367\end{array}$

18.14 Logic circuit design from a Boolean equation 369

\begin{tabular}{ll}
18.15 & Computer listings \\
\hline
\end{tabular}

$\begin{array}{ll}\text { Exercises } & 374\end{array}$

Summary of important facts $\quad 376$

19 Complex numbers $\quad 377$

$\begin{array}{lll}19.1 & \text { Introduction } & 377\end{array}$

$\begin{array}{lll}19.2 & \text { The operator } j & 377\end{array}$

19.3 The rectangular form and polar form of a complex number 379

$\begin{array}{lll}19.4 & \text { The effect of a negative magnitude } & 384\end{array}$

$\begin{array}{ll}19.5 & \text { Addition of complex numbers } \\ & 385\end{array}$

$\begin{array}{ll}\text { 19.6 Subtraction of complex numbers } & 387\end{array}$

19.7 Multiplication of complex numbers 388

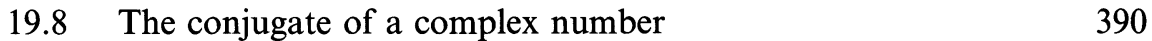

19.9 Division of complex numbers 391

19.10 Impedance in complex numbers 393

$\begin{array}{lll}19.11 \text { Ohm's law for a.c. circuits } & 396\end{array}$

$\begin{array}{lll}19.12 & \text { Three-phase calculations } & 398\end{array}$

$\begin{array}{ll}19.13 \text { Computer listings } & 400\end{array}$

Exercises $\quad 403$

Summary of important facts $\quad 404$

20 Computer solution of electronic and electrical circuits 407

20.1 Introduction 407

20.2 The concept of SPICE 407

20.3 A simple introductory example 408

20.4 Solving a d.c. network 411 
20.5 SI multiples in SPICE

413

20.6 Resistance-temperature coefficient 414

20.7 A series $R-L-C$ a.c. circuit $\quad 416$

20.8 A parallel a.c. circuit 419

20.9 A simple transistor amplifier 421

20.10 An inverting summing amplifier $\quad 425$

20.11 A non-inverting amplifier 427

20.12 Low-pass, high-pass and band-pass filters 429 Exercises $\quad 434$

Summary of important facts $\quad 436$

Answers to exercises 437

Bibliography 448

Index 449 
1.1 Variation of resistance of a conductor with temperature $\quad 10$

1.2 Graph for Worked Example 1.7 13

$\begin{array}{ll}1.3 & \text { International colour code for resistor values } \\ 2 & 15\end{array}$

$\begin{array}{lll}2.1 & \text { Three resistors in series } & 21\end{array}$

2.2 A three-branch parallel circuit 24

2.3 Circuit for Worked Example 2.5 27

2.4 Solution of Worked Example 2.5 27

2.5 Circuit for Worked Example 2.6 29

2.6 Solution for Worked Example 2.6 30

$\begin{array}{lll}2.7 & \text { The Wheatstone bridge } & 31\end{array}$

2.8 Circuit for Worked Example 2.7 33

2.9 Circuit for Exercise 2.11 38

2.10 Circuit for Exercise 2.13 39

2.11 Circuit for Exercise 2.14 39

3.1 Circuit for Worked Example 3.5(b) 45

4.1 Illustration of Kirchhoff's Current Law (KCL) 56

4.2 Illustration of Kirchhoff's Voltage Law (KVL) 56

4.3 A simple application of KVL 57

4.4 Circuit for Worked Example 4.1 58

4.5 Circuit for Worked Example 4.2 59

4.6 Circuit for Worked Example 4.3 61

4.7 Thévenin's theorem 65

4.8 Circuit for Worked Example 4.4 65

4.9 Solution of Worked Example 4.4 66

4.10 Circuit for Worked Example 4.5 67

4.11 Thévenin determination 68

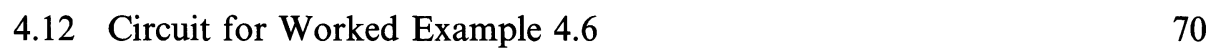

4.13 Calculation of $E_{T}$ for Worked Example 4.6 70

4.14 Determination of $R_{T}$ for Worked Example 4.6 71

4.15 The Thévenin equivalent circuit between nodes $B$ and $D$ for the
circuit in Figure 4.12

4.16 Circuit representation of a practical current source (the Norton
equivalent circuit)

4.17 Circuit for Worked Example 4.7 74 
4.18 Determination of the current in resistor $R_{L}$

4.19 Circuit diagram for Worked Example 4.8 76

4.20 Circuit for the final solution of Worked Example 4.8 77

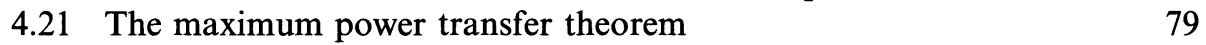

4.22 Circuit for Exercise 4.1 82

4.23 Circuit for Exercise 4.2 83

4.24 Circuit for Exercise 4.3 83

4.25 Circuit for Exercise 4.4 83

4.26 Circuit for Exercise 4.5 84

$\begin{array}{lll}5.1 & \text { Series-connected capacitors } & 91\end{array}$

5.2 Parallel-connected capacitors 94

5.3 Circuit for Worked Example 5.13 97

5.4 Circuit for Worked Example 5.14 99

5.5 Figure for Worked Example 5.15 100

$\begin{array}{ll}6.1 \text { Symbol for an inductor } & 109\end{array}$

$\begin{array}{ll}6.2 & \text { Mutually coupled coils } \\ 6.14\end{array}$

6.3 Series-connected inductors having no mutual coupling between them

6.4 Two series-connected coils which are mutually coupled 117

6.5 Parallel-connected inductors 118

6.6 Circuit for Worked Example 6.15 120

7.1 e.m.f. induced in a conductor when it moves at an angle to the magnetic field

$\begin{array}{lll}\text { 7.2 } & \text { Circuit for Worked Example 7.9 } & 134 \\ 7.3 & B-H \text { curve for Worked Example 7.10 } & 136\end{array}$

$\begin{array}{lll}7.4 & \text { Parallel magnetic circuits } & 137\end{array}$

7.5 Magnetic circuit for Worked Example 7.11 138

7.6 Magnetic circuit for Exercise 7.19 146

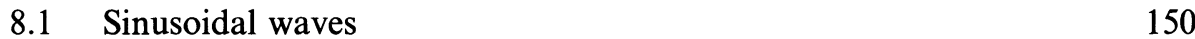

8.2 Triangular and rectangular waves 151

$\begin{array}{ll}\text { 8.3 Phase angle of a sinusoidal wave } & 160\end{array}$

8.4 Drawing phasors 164

8.5 Addition of phasors 165

8.6 Relationship between rectangular and polar coordinates 166

8.7 Phasor diagram for Worked Example 8.16 168

8.8 Phasor diagram for Worked Example $8.17 \quad 170$

$\begin{array}{lll}8.9 & \text { Subtraction of phasors } & 171\end{array}$

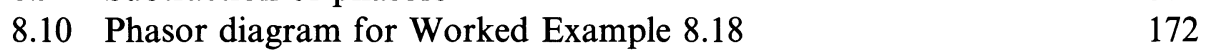

9.1 The $R$ - $L$ series circuit 184

9.2 Phasor diagram for Worked Example 9.1 185

$\begin{array}{lll}9.3 & \text { The } R-C \text { series circuit } & 187\end{array}$

9.4 Phasor diagram for Worked Example 9.3 189

9.5 Phasor diagram for Worked Example 9.4 190

9.6 The $R$ - $L$ - $C$ series circuit 191

9.7 Circuit diagram and phasor diagram for Worked Example $9.4 \quad 192$

9.8 Phasor diagram for Worked Example 9.5 194

9.9 Circuit diagram and phasor diagram for a parallel $R-L$ circuit 195 
9.10 Circuit diagram and phasor diagram for a parallel $R-C$ circuit

9.11 Circuit diagram and phasor diagram for a practical parallel circuit

9.12 Circuit diagram and phasor diagram for Worked Example $9.8 \quad 200$

10.1 The power triangle

10.2 Phasor diagram for Worked Example 10.2

10.3 Phasor diagram and power triangle for Worked Example 10.4 217

10.4 Graphical solution of Worked Example 10.5 219

$\begin{array}{lll}10.5 & \text { Power factor correction } & 220\end{array}$

10.6 Phasor diagram for Worked Example $10.6 \quad 222$

11.1 The series resonant circuit 229

11.2 Pure $L$ in parallel with pure $C$ at resonance 232

11.3 $L-R$ in parallel with pure $C$ at resonance 234

$\begin{array}{lll}11.4 & \text { Phasor diagram for Worked Example 11.4 } & 237\end{array}$

12.1 Ideal two-winding transformer 243

12.2 Graph showing how the efficiency of a transformer varies with load current

12.3 No-load phaser diagram for a simple transformer 250

12.4 No-load equivalent circuit for the simple transformer 250

12.5 Phasor diagram for a transformer with an inductive load 252

12.6 Simplified equivalent circuit of a transformer 253

$\begin{array}{lll}12.7 & \text { The auto-transformer } & 255\end{array}$

$\begin{array}{ll}\text { 13.1 The basic three-phase alternator } & 265\end{array}$

$\begin{array}{lll}13.2 & \text { Balanced star-connected system } & 267\end{array}$

13.3 Three-phase, four-wire, star-connected system 269

13.4 Phasor diagram for Worked Example 13.3 272

13.5 Circuit diagram and phasor diagram for Worked Example 13.4 274

13.6 Delta or mesh connection 276

$14.1 \quad p-n-p$ transistor configurations 286

14.2 Fixed bias circuit for a common-emitter $p-n-p$ amplifier 287

14.3 Collector bias circuit for a $p-n-p$ common-emitter amplifier $\quad 289$

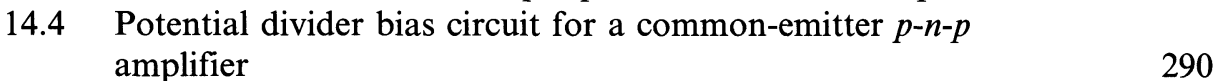

14.5 A common-emitter class A amplifier 292

14.6 Graph for Worked Example 14.4 293

14.7 The a.c. load line or dynamic load line 296

14.8 Load line for Worked Example 14.5 298

$14.9 \quad p-n-p$ emitter follower circuit $\quad 299$

14.10 Field-effect transistors 300

15.1 Circuit representation of an op-amp 305
15.2

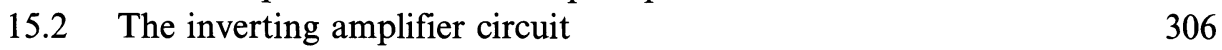

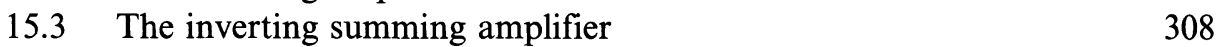

$\begin{array}{ll}15.4 & \text { A non-inverting amplifier } \\ 15.5\end{array}$

15.5 Differential amplifier or instrumentation amplifier 311

15.6 A popular form of practical instrumentation amplifier 311

$\begin{array}{lll}15.7 & \text { An electronic integrator circuit } & 313\end{array}$

16.1 Discrete component $R$ - $C$ phase-shift oscillator 319 
16.2 An op-amp Wein-bridge oscillator 320

16.3 An op-amp twin-T oscillator 321

16.4 A Colpitts oscillator 322

16.5 A Hartley oscillator 324

16.6 A discrete component tuned collector oscillator 326

$\begin{array}{ll}\text { 16.7 A popular astable multivibrator circuit } & 327\end{array}$

16.8 An op-amp symmetrical astable multivibrator 327

$\begin{array}{lll}17.1 & \text { Cascaded stages } & 337\end{array}$

17.2 T-and $\pi$ attenuators 338

17.3 Figure for Worked Example $17.6 \quad 341$

17.4 T-to- $\pi$ and $\pi$-to-T conversion $\quad 342$

$\begin{array}{lll}17.5 & \text { Filter circuit characteristics } & 344\end{array}$

17.6 Passive $R$ - $C$ low-pass filter $\quad 344$

17.7 Passive $R$ - $C$ high-pass filter 346

17.8 A phase-inverting active $R$ - $C$ low-pass filter 348

17.9 A phase-inverting active $R$ - $C$ high-pass filter 348

18.1 International symbols for logic gates 368

18.2 Simple versions of NAND and NOR gates 369

18.3 Block diagram for Worked Example $18.10 \quad 371$

18.4 Block diagram for Exercise 17.15 375

$\begin{array}{lll}19.1 & \text { Introduction to the operator } j & 378\end{array}$

19.2 Further information about the operator $j \quad 378$

19.3 Rectangular and polar form of a complex number 380

19.4 The Argand diagram for the complex numbers in Worked Example 19.1

19.5 The Argand diagram for the complex numbers in Worked

Example $19.2 \quad 382$

19.6 The effect of a negative magnitude 384

19.7 The conjugate of a complex number 390

19.8 Impedance triangle for (a) an $R-L$ series circuit (b) an $R$ - $C$ series circuit $\quad 393$

19.9 Phasor diagram for Worked Example $19.14 \quad 398$

20.1 Circuit for Worked Example 20.1 408

20.2 Circuit for Worked Example 20.2 411

20.3 Circuit for Worked Example 20.3 414

20.4 Circuit for Worked Example 20.4 416

20.5 Circuit for Worked Example 20.5 419

20.6 Solution of Worked Example 20.6 422

20.7 Circuit for Worked Example 20.7 425

20.8 Circuit for Worked Example 20.8 427

20.9 Circuit for Worked Example $20.9 \quad 430$

20.10 PROBE print-out of the results of Worked Example 20.9

20.11 Circuit for Exercise 20.6 435

20.12 Circuit for Exercise $20.7 \quad 435$ 
1.1 A list of typical SI units 5

1.2 Multiples of 10 used with the SI system 6

$\begin{array}{lll}1.3 & \text { International colour code used for resistors } & 14\end{array}$

1.4 Resistor values used with colour codes 15

$7.1 B, H$ and $\mu_{r}$ for cast steel 132

$\begin{array}{lll}7.2 & \text { Table for Exercise 7.16 } & 145\end{array}$

7.3 Table for Exercise 7.19 146

14.1 Table for Worked Example 14.4 293

14.2 Table for Worked Example 14.5 297

17.1 Table of decibel values 336

18.1 Basic numbering systems 358

18.2 Truth table for full-addition 362

18.3 Truth table of basic gates 368

18.4 Truth table for Worked Example $18.10 \quad 371$

18.5 Truth table for Exercise 18.14 375

18.6 Truth table for Exercise 18.16 375

20.1 PSpice input file for Worked Example 20.1 409

20.2 PSpice small signal bias solution for Worked Example 20.1 410

20.3 Input file for Worked Example 20.2 412

20.4 Small signal bias solution for Worked Example $20.2 \quad 413$

20.5 SPICE multiples 413

20.6 Input file for Worked Example 20.3 415

20.7 Temperature-adjusted values for Worked Example 20.3 415

20.8 Input file for Worked Example 20.4 417

20.9 a.c. analysis for Worked Example $20.4 \quad 418$

20.10 Input file for Worked Example 20.5 $\quad 420$

20.11 Output file for Worked Example 20.5 421

20.12 Input file for Worked Example 20.6 423

20.13 Output file for Worked Example 20.6 424

20.14 Input file for Worked Example $20.7 \quad 426$

20.15 Output file for Worked Example 20.7 427

20.16 Input file for Worked Example 20.8 428

20.17 Output file for Worked Example 20.8 428

20.18 Input file for Worked Example 20.9 431

20.19 a.c. analysis for Worked Example 20.9

20.20 Printer output for the '.PLOT' line in Worked Example 20.9 
$\begin{array}{lll}1.1 & \text { SI multiple converter } & 16\end{array}$

$\begin{array}{lll}1.2 & \text { Temperature-dependent resistance calculations } & 17\end{array}$

2.1 Resistance of series- and parallel-connected resistors 34

2.2 Voltage distribution between series resistors 36

2.3 Current distribution between parallel resistors 37

3.1 Calculation of power, energy and efficiency 50

$\begin{array}{lll}4.1 & \text { Solution of two simultaneous equations } & 80\end{array}$

4.2 Relationship between Thévenin and Norton 81

5.1 Capacitance of a parallel-plate capacitor, and charge and energy $\begin{array}{ll}\text { stored in a capacitor } & 102\end{array}$

5.2 Capacitance of series- and parallel-connected capacitors 103

$\begin{array}{lll}5.3 & \text { Voltage distribution between series-connected capacitors } & 104\end{array}$

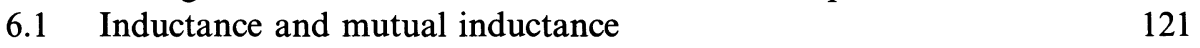

$\begin{array}{ll}7.1 & \text { Equations for electromagnetism } \\ 8.1 & 141\end{array}$

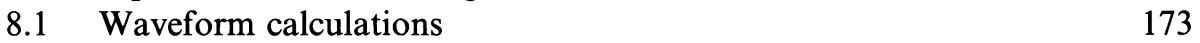

8.2 Addition and subtraction of phasors 176

$9.1 \quad R-L-C$ a.c. series circuit analysis 203

$9.2 R-L-C$ two-branch a.c. circuit analysis 204

9.3 Solution of a right-angled triangle 206

$\begin{array}{ll}10.1 & \text { Solution of a power triangle } \\ 10.2 & 224\end{array}$

$\begin{array}{lll}10.2 & \text { Power factor calculations } & 224\end{array}$

11.1 Resonant frequency and impedance at resonance 238

12.1 Transformer calculations 257

$\begin{array}{ll}\text { 13.1 Three-phase calculations for balanced systems } & 279\end{array}$

14.1 Common-emitter bias calculations 300

15.1 Phase inverting summing amplifier 315

$\begin{array}{ll}15.2 & \text { Operational amplifier integrator } 315\end{array}$

16.1 Oscillation frequency of popular oscillator circuits 328

17.1 Conversion of numerical gain to decibels and decibels to
numerical gain

17.2 Attenuator calculations 351

17.3 T- $\pi$ and $\pi$-T conversion for resistive networks 352

$17.4 R$ - $C$ filters 353

18.1 Converting a decimal value to a binary value 372

18.2 Converting a binary number to decimal 373

19.1 Rectangular to polar conversion 400

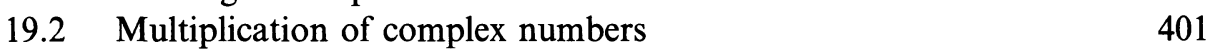

19.3 Division of complex numbers by one another 402 
This book deals with the methods and techniques used in problem solving in Electronic and Electrical circuits, ranging from manipulating equations to opamp circuits, logic circuits and power engineering

The material is presented in the form of 'what you need to know first, is dealt with first'. The author has made every effort to cover all the topic area in a large subject matter, and the text is supported by many worked examples and informative diagrams.

Since each section is self-contained, the more experienced reader can turn to the section they are interested in and deal with that topic.

The book covers all the Principles for BTEC National Certificate in Electronic and Electrical Engineering courses, and a very considerable part of the Principles for Higher National Certificates. It will be invaluable for students requiring further explanation of the solution of problems in electronic and electrical engineering, since methods of carrying out computations are both fully and clearly explained.

As colleges move into the GNVQ philosophy, more emphasis is placed on students researching and learning for themselves, and this book will be an invaluable resource.

Each chapter commences with an introduction which describes the basic theory involved, followed by a range of worked examples. The concluding section of each chapter describes computer listings in the BASIC language, which are particularly suitable for the type of problems in that chapter.

This book will provide invaluable support for the following:

- NVQ and GNVQ Levels II and III

- BTEC National and Higher National Electronics/Electrical courses

- C \& G LI Parts II and III

- 'A' level Electronics courses

- 1st Year Electronics/Electrical/Physics degrees

- Home constructors who need to understand the 'why' as well as 'how'.

Further information about the software is contained in 'A note about the computer programs' on $\mathrm{p}$. xxii. 
Chapter 20 describes the use of SPICE software, which is widely available, and can be used to solve almost any type of electronic or electrical problem, details of which are given on pp. xxii and xxiii.

Each chapter also contains a large number of exercises on which the reader can test their skill; the solution to the exercises is provided at the end of the book (p. 437). The exercises have been presented in the order in which they appear within the chapter and, within this grouping, they have been graded in order of difficulty. Finally, each chapter is concluded by a summary of important facts, which provides an easy to read summary of the vital data in the chapter.

A bibliography of other related titles in the Masters series is given at the end of the book.

The book is designed to suit the busy reader, so that you can quickly obtain the information you need about solving a particular type of problem.

The reviewers of the book deserve many thanks for their very helpful and constructive comments.

I would like to thank Mr P. Goss, Technical Manager of ARS Microsystems, for his advice and assistance in connection with Chapter 20, where the use of PSpice software is described. I am indebted to $\mathrm{Mr} \mathrm{A}$. Lewis, Head of Management Services, Longdean, Hemel Hempstead, for advice received. Finally, I would like to thank my wife for her support, without which the writing of this book would not have been possible.

NoEl M. Morris 
The computer programs in this book are written in QUICK BASIC, and some minor amendments may be required to the programs for use in other BASIC dialects. The programs have been written using line numbers (which, strictly speaking, is not necessary for QUICK BASIC) so that simple instructions such as GOTO can be used. On the whole, simple programming techniques have been adopted so that the programs are easy to understand.

Many of the programs introduce the reader to the use of menus and other topics. The programs enable the reader to gain expertise in program writing, and they may easily be modified by adding extra lines to them. If syntax errors occur during the loading of the programs, it may mean that some characters such as parenthesis, commas or semicolons have either been overlooked or changed by the reader. Any errors can be corrected by studying the manual for your computer.

To save the reader the effort of entering the programs into their computer, all of the programs in the book are available from:

AVP Educational Software

School Hill Centre

Chepstow

Gwent NP6 5PH

Tel: 01291625439

Fax 01291629671

The AVP catalogue number is COM 476. All the BASIC files on the disc have the extension '.BAS', and are stored in a text format so that they may be transferred to any word processor. The manual for the disc is also available on the disc in the file MANUAL.TXT, which is in a text format which may be read by any word processor.

Also included on the disc are a number of PSpice files associated with Chapter 20, including 17 '.OUT' files, together with other files relating to PSpice (a total of 74 files in all on the disc). The files which describe the circuits have the extension '.CIR', and other files have the extension '.CFG' or '.DAT'. Files which contain the results have the extension '.OUT'; these files also contain the PSpice circuit description which is identical to that in the corresponding '.CIR' file. An 
advantage of having the '.OUT' files is that they may be read by a word processor, and it is not necessary to have PSpice software installed in your own computer in order to study them. Readers need PSpice installed in their computer in order to run '.CIR' files.

All the programs in Chapter 20 (and for many problems in other chapters) were developed using PSpice software. Versions of this software for PCs usually have on-disc documentation, and is available from the address below. The software is also available through the pages of magazines dealing with computer shareware.

ARS Microsystems

Herriard Business Centre

Alton Road

Basingstoke RG25 2PN

The majority of the Worked Examples and Exercises in this book have been checked by the use of either the BASIC language programs or by PSpice. 